\title{
Initiation of Diabetes Treatment: Variations from Current Guidelines
}

\author{
Ashrafuzzaman $\mathrm{SM}^{\mathrm{a}}$, Mir AS ${ }^{\mathrm{b}}$, Latif ZA
}

\begin{abstract}
Background: Bangladesh is a developing country with a population of 160 million, diabetes prevalence of 6$10 \%$ and $85-90 \%$ being type 2. Most diabetic patients receive treatment by general practitioners because of scarcity of Endocrinologist and Diabetologists. But, by most of them, initiation of diabetes treatment along with lifestyle is not always in accordance to any guideline proposed by ADA, EASD, AACE, IDF, WHO etc. The current study was designed to find out the practice of follower of Diabetes Guidelines.

Methods:From January to December 2014, 1745 prescriptions for newly detected type 2 diabetes were recorded. Their age and BMI, FPG, 2-h PG and HbAlc were recorded.

Results: Mean age was $42 \pm 12$ years and mean BMI was $25 \pm 4.2 \mathrm{Kg} / \mathrm{m}^{2}$. Mean FPG $9.4 \pm 1.2 \mathrm{mmol} / \mathrm{L}$ and $2-\mathrm{h}$ $P G 17.7 \pm 3.4 \mathrm{mmol} / \mathrm{L}$ and mean HbAlc was (done in 235 subjects) $9.1 \pm 1.3 \%$.

Along with lifestyle, metformin (Met) alone (9\%), sulfonylurea (SU) alone (8\%), Met+SU(41\%), Met + DPPIVi(22\%), Met plus insulin (7\%) were prescribed. Lifestyle alone (6\%) and 3 drugs together (insulin, Met, SU/DPP IVi) (7\%) were also prescribed. Many of the prescriptions were not in accordance with established guidelines.

Conclusion: Current survey concludes that the well accepted guidelines are not properly followed in many newly detected type 2 diabetic subjects. However, every patient is different, so, every aspects of a patient including co-morbidities should be taken in to account before prescribing, still physicians should be aware of existence of guidelines and their utility.
\end{abstract}

Key words: Guidelines; treatment initiation; type 2 diabetes mellitus should be aware to the Guidelines and guidelines are important for primary care physician.

(BIRDEM Med J 2016; 6(2): 91-94)

\section{Introduction}

Bangladesh is a fast developing country and population is about 160 million. ${ }^{1}$ Different studies showed 6-10\% population is diabetic and mostly $(85-90 \%)$ are type 2 diabetes (T2DM). ${ }^{2,3}$ Doctor patient ratio is $1: 8000 .^{3,4}$ Among the physicians, approximately 100 are diabetologists and endocrinologists, engaged in clinical

\section{Author Informations}

a. Prof.SM Ashrafuzzaman, Professor, Department of Endocrinology, BIRDEM

b. Dr. Ahmed Salam Mir, Assistant Registrar, Department of Endocrinology, BIRDEM

c. Prof. Zafar Ahmed Latif, Director, BIRDEM Academy and Professor of Endocrinology, BIRDEM

Address of correspondence: Prof.SM Ashrafuzzaman, Professor, Department of Endocrinology, BIRDEM. Email: ashrafzaman 1961@gmail.com

Received: September 30, 2015

Accepted: May 30, 2016 practice. Others are medical specialists or certified diabetologists and general practitioners (GPs), those who are taking care of most of the diagnosed diabetic subjects. Bangladesh Institute of Research and Rehabilitation in Diabetes, Endocrine and Metabolic Disorders (BIRDEM), one of the tertiary care Institute of Bangladesh Diabetic Somity(BADAS), the largest Diabetic Association of the world having its network all over the country to provides service and development of skilled manpower. The doctors working under this umbrella network are engaged mostly for initiation of diabetes treatment other than medical specialist and GP's. They used to start by 3D's(Diet, Drug and Discipline). But they, along with lifestyle measures, do not always start drugs according to any guideline proposed by ADA, EASD, AACE, IDF, WHO etc. specially for combination therapy [4-6]. ${ }^{5-7}$ Though most 
popular guideline is believed to be $\operatorname{ADA}$ (American Diabetic Association) but in practice much variation is seen from the initiation (selection of drugs). There is no comparative analytical report between followers and non-followers of guideline about outcome.

Initial treatment of patients with T2DM includes education, with emphasis on lifestyle changes including diet, exercise and weight reduction when appropriate. Monotherapy with metformin is indicated for most patients and insulin may be indicated for initial treatment for some. ${ }^{8}$ Although several studies have noted remissions of T2DM, that may last several years, most patients probably require continuous treatment in order to maintain normal or near-normal glycemia. Regardless of the initial drug and response to therapy, the natural history of most patients with T2DM is the deterioration of beta-cell function.

Most patients will need dual therapy to achieve target blood glucose and HbAlc. Choice of second agent is very vital. All the drugs are compared for their efficacy, safety, hypoglycemic risk, weight change, adverse effects as well as cost. After a successful initial response to oral therapy, patients fail to maintain target A1C levels $(<7 \%)$ at a rate of 5 to 10 percent per year (UKPDS). An analysis from the United Kingdom Prospective Diabetes Study (UKPDS) found that 50 percent of patients originally controlled with a single drug required the addition of a second drug after three years; by nine years 75 percent of patients needed multiple therapies to achieve the target $\mathrm{HbA} 1 \mathrm{c}$ value $<7 \%$. With treatment, monitoring and evaluation for micro-vascular and macro-vascular complications are to be assessed. ${ }^{9}$ All patients eventually need insulin, in spite of T2DM, due to its progressive nature and gradual deterioration of beta cell function.

The consensus algorithm recommends testing $\mathrm{HbA} 1 \mathrm{c}$ levels in every three months and addition of a second medication when the treatment goal of $\mathrm{HbAlc}<7 \%$ with metformin plus lifestyle intervention is not achieved within three months. ${ }^{11}$ In order to achieve the glycaemicgoal, the following glucose goals are usually necessary: fasting glucose 70 to $130 \mathrm{mg} / \mathrm{dL}$ (3.89 to $7.22 \mathrm{mmol} / \mathrm{l}$ ) and postprandial glucose (90 to 120 minutes after a meal $)<180 \mathrm{mg} / \mathrm{dL}(10 \mathrm{mmol}) .{ }^{11}$

\section{ADA/EASD Guideline}

In ADA/EASD guideline, it is ascribed as adopted for adult T2DM, non-pregnant, relatively healthy individual with mild to moderate hyperglycemia (newly detected $\mathrm{DM})$, to start with and to maintain healthy lifestyle
(Healthy eating, Weight control, Increased Physical Activity), start as monotherapy with metformin. Of course, they guided to consider, efficacy (HbA1c lowering capacity), hypoglycemia, weight, side effect and cost of the drug. Then if needed, to reach individual target of HbA1c after $\sim 3$ months, proceed to second line(2 Drug Combination). The choice of second drug is tricky. One can choice either of $\mathrm{SU}$ (Sulfonylurea), TZD(Thiazolidinedione), DPP4i( DPP IV Inhibitors), GLP-1RA(GLP-1 Receptor Agonist),BI (basal insulin); (eg. LS+Met+DPP4i). If this 2 drug regime fails to achieve $\mathrm{HbAl} \mathrm{c}$ at target in next 3 months or to maintain it, add $3^{\text {rd }}$ agent from these 5 agents (eg. $\mathrm{LS}+\mathrm{Met}+\mathrm{DPP} 4 \mathrm{i}+\mathrm{SU}$ or LS+Met+DPP4i+bI).

For all patients consider to initiate dual therapy ( 2 drugs) when initial $\mathrm{HbA} 1 \mathrm{c}>9.0 \%$ to more expeditiously achieve the target HbAlc. If weight loss or ketosis is present start insulin. Start insulin if HbA1c > 10-12\% or FPG $>16.7 \mathrm{mmol} / \mathrm{L}$. After resolving glucotoxicity, the regimen can be simplified subsequently.

\section{AACE Guideline}

The AACE guideline for initiation of diabetes treatment, along with lifestyle it is based on HbAlc. If initial A1c $<7.5 \%$ start monotherapy with any drug but preferably metformin if not contraindicated. But if A $1 \mathrm{c}>$ $7.5 \%$ start 2-3 drugs like LS+Met+DPP4i. SU or non$\mathrm{SU}$ are considered last as initial therapy. Rather if 3 drugs are to start, it is better to consider one basal insulin or GLP-1RA (Liraglutide, Albiglutideetc). If $\mathrm{HbA1c}>$ $9.0 \%$ and patient is symptomatic (Classical), it is better to start insulin \pm other agents.

\section{IDF Guideline}

According to IDF in T2DM, metformin should be the first choice, if contraindicated SU can be started. Choice at $2^{\text {nd }}$ line may be according to individual need and acceptable from SU, AGI, DPP4i TZD etc. Finally basal or premixed insulin can be initiated as $3^{\text {rd }}$ line with OAD. Maximum 3 OAD can be used of different mechanism of action.

In general practice according to proposed guideline of Certificate Course in Diabetology (CCD) of Distance Learning Program(DLP) run by Bangladesh Diabetic Somity(BADAS), there are 3 categories of initial prescription according to $\mathrm{HbA} 1 \mathrm{c}$ and FPG. If $\mathrm{HbA} 1 \mathrm{c}$ $<8 \%$ and or $\mathrm{FPG}<11.1 \mathrm{mmol} / \mathrm{L}$ start $\mathrm{LS} \pm$ Met, if $\mathrm{HbA} 1 \mathrm{c} 8 \%-10 \%$ and or FPG $11.1-13.9 \mathrm{mmol} / \mathrm{L}$ start 2 drugs. One is metformin $2^{\text {nd }}$ may be $\mathrm{SU}$ or others. If 
HbAlc $>10 \%$ and or symptomatic, FPG $>14.0 \mathrm{mmol} /$ $\mathrm{L}$ one agent should be insulin.

So, considering all issues of pathophysiology,specially of T2DM, as initial treatment when monotherapy is practical, start with metformin along with lifestyle. But few of them will require dual therapy as initial treatment. Choice of second agent is very vital. It needs scientific data and also experience. More than 3 oral drugs should not be practiced. It is better to initiate insulin (basal or premixed once daily) earlier.

\section{Methods}

From January to December2014, 1745 newly detected clinically T2DM, who were prescribed their first treatment was recorded (Initiation of diabetes treatment). Data were recorded from each prescription for age, sex, height, weight, BMI, fasting plasma glucose (FPG), 2$\mathrm{h}$ post glucose (as part of OGTT). The names of the drugs as generic (oral or insulin or combination) were recorded.

Prescribed treatment was compared with ADA/EASD algorithm published in January 2015. All the prescriptions were done by physicians working in this field for $>5$ years. All consecutive prescriptions of "new case, first prescription" were recorded.

The data were analyzed by using SPSS for windows 16 software package. Values were expressed as a percentage of each group or as mean \pm SE, unless otherwise stated. Chi square test $\left(\mathrm{x}^{2}\right)$ or Fisher exact test were used for the comparison of qualitative data. Spearman correlation (for non parametric data) or Pearson correlation (for parametric data) were used to establish correlation. Results were considered statistically significant at $\mathrm{P}<0.05$.

\section{Results}

Total 1745 prescriptions were analyzed. Females were 1032 (59.15\%) and males 713 (40.85\%). Base-line characteristics are presented in table I.

\begin{tabular}{|c|c|c|c|}
\hline \multicolumn{4}{|c|}{$\begin{array}{l}\text { Table I. Baseline Characteristics of the Study } \\
\text { Subjects }\end{array}$} \\
\hline Paraemeter & Mean & $\pm \mathrm{SD}$ & $\mathrm{n}(\%)$ \\
\hline Age (years) & 42 & 12 & \\
\hline $\operatorname{BMI}\left(\mathrm{Kg} / \mathrm{m}^{2}\right)$ & 25 & 4.2 & \\
\hline Family history of DM & & & $942(54)$ \\
\hline HbA1c $(\%)$ & 9.1 & 1.3 & $235(13.46)$ \\
\hline $\mathrm{FPG}(\mathrm{mmol} / \mathrm{L})$ & 9.4 & 1.2 & \\
\hline 2-h post glucose $(\mathrm{mmol} / \mathrm{L})$ & 17.7 & 3.4 & \\
\hline Serum creatinine(mg/dL) & 1.01 & 0.07 & $278(15.9)$ \\
\hline
\end{tabular}

Among the prescriptions studied, only lifestyle advices were given in 105 (6\%). Other patients received lifestyle advices along with medications as shown in table II. Comparison of different prescript[tions are shown in tables III and IV.

\section{Table II. Lifestyle with different Drugs}

\begin{tabular}{lcc} 
Drugs & $\mathrm{n}$ & $\%$ \\
\hline Metformin monotherapy & 157 & 9 \\
Met+DPP4i & 384 & 22 \\
Met+ SU & 664 & 38 \\
SU alone & 140 & 8 \\
DP4 i monotherapy & 07 & $<1$ \\
Insulin monotherapy & 08 & $<1$ \\
Metformin + Insulin & 123 & 7 \\
Insulin+SU & 34 & 2 \\
Lifestyle monotherapy & 105 & 6 \\
3Drugs(SU+Met+otherOAD/ & 123 & 7 \\
SU+Met+Dpp4i) & & \\
\hline Total & 1745 & 100 \\
\hline
\end{tabular}

NB: No TZD, AGI, GLP-1RA was found as initiation of treatment.

TableIII. Comparison of LS+Metforminmonotherapy with others as initial treatment

\begin{tabular}{|c|c|c|c|c|c|c|}
\hline & $\mathrm{n}$ & $\begin{array}{c}\text { FPG } \\
\text { Mean } \pm \text { SD }\end{array}$ & $\begin{array}{l}\text { p-value } \\
\text { (FPG) }\end{array}$ & $\begin{array}{c}\mathrm{HbA} 1 \mathrm{c} \% \\
\operatorname{Mean} \pm \mathrm{SD}(\mathrm{n})\end{array}$ & $\begin{array}{c}\text { p-value } \\
\text { (HbAlc) }\end{array}$ & Comparison \\
\hline Metformin & 157 & $8.8 \pm 1.4$ & - & $8.9 \pm 0.6(62)$ & - & - \\
\hline $\mathrm{Met}+\mathrm{SU}$ & 664 & $9.1 \pm 1.7$ & NS & $9.1 \pm 1.1(25)$ & NS & $\mathrm{Met} / \mathrm{Met}+\mathrm{SU}$ \\
\hline Insulin \pm Met & 131 & $15.3 \pm 1.7$ & $<0.01$ & $9.4 \pm 1.5(87)$ & 0.044 & Met/Met+Ins \\
\hline
\end{tabular}


Table IV. FPG and HbAlc among the insulin initiators

\begin{tabular}{lccc}
$\mathrm{n}=165(9.4 \%)$ & Total Insulin & FPG mmol/L & HbA1c $\%$ \\
\hline $\begin{array}{l}\text { Insulin+ Metn=131 } \\
\text { Insulin+SUn=34 }\end{array}$ & $\mathrm{n}=165$ & $14.7 \pm 2.1$ & $9.2 \pm 1.9$ \\
\hline
\end{tabular}

\section{Discussion}

According to ADA/EASD(American Diabetic Association)/(European Association for Study of Diabetes) guidelines, if not contraindicated treatment should be started with LS+Met. According to AACE (American Association of Clinical Endocrinologists') initial treatment is based on $\mathrm{HbAlc}$; if 7.5\%-9.0\% start with monotherapy preferably Met. Dual or triple therapy or even insulin should be started in patients with symptoms (typical) if, $\mathrm{HbA} 1 \mathrm{c}>9.0 \%$. Other guidelines like IDF (International Diabetes Federation), WHO also favors these guidelines with very few modifications. TZD either alone or in combination with metformin was not prescribed due confusion as "Band Item in Bangladesh".

But, in this study group, most of the cases of newly detected $\mathrm{T} 2 \mathrm{DM}$, treatment was started with 2 drugs Met $+\mathrm{SU}$ or Met+DPP4i (63\%). Insulin was given mostly based on FPG ( If $>14-16 \mathrm{mmol} / \mathrm{L}$ ), not $\mathrm{HbA} 1 \mathrm{c}$. HbAlc was tested in $13.4 \%$ patients only and serum creatinine was tested only in $16 \%$ subjects at diagnosis and up to initiation of treatment. In most groups, definite guideline was not followed, neither FPG nor HbA1c dependent guidelines. Regarding treatment initiation, most patients experienced monotherapy or combination therapy. May be, many of our patients diagnosed late and Met monotherapy will not suffice to achieve the target. Further controlled trials may give the correct answer of the questions.

Regarding initiation with insulin, the first guideline advocated for start with basal insulin once daily with OAD and gradually intensify according to need. But, now-a-days, in guidelines either basal or premixed, preferably analogue can be started as once daily basis. The OAD should be continued with once daily insulin. But, when twice daily insulin is started or intensification is done, it is better to keep only Met or insulin sensitizers with insulin.

Like our observations, many reports showed that these established guidelines are not properly followed. ${ }^{12,13}$

\section{Conclusion}

From the current survey, it can be concluded that, the well accepted guidelines are not properly followed in newly detected T2DM subjects. Prescribers should be aware of the situation, however every patient is different, so, every aspects of a patient including co-morbidities should be taken in to account before prescribing. Clinician should be aware of guidelines and guidelines guides primary care physician.

Conflict of interest: None.

\section{References}

1. IDF Diabetes Atlas $4^{\text {th }}$ ed. International Diabetes Federation 2009.

2. Expert Committee on the Diagnosis and Classification of Diabetes Mellitus. Report of the expert committee on the diagnosis and classification of diabetes mellitus. Diabetes Care 2001; 24(Supp1. 1): S5-S29.

3. Sayeed MA, Mahtab H, Khanam PA, Latif ZA, Ali SM, Banu A, et al. Diabetes and Impaired Fasting Glycemia in a Rural Population of Bangladesh. Diabetes Care 2003; 26 (4):1034-39.

4. BBS(Bangladesh Bureau of Statistics).Statistical Yearbook 2012. www.bbs.gov.bd

5. American Diabetes Association. Standard of medical care in diabetes 2010. Diabetes Care 2013; 36 (Suppl. 1): S11-S62.

6. UK Prospective Diabetes Study (UKPDS) Group. Effect of intensive blood glucose control with metformin on complications in overweight patientsbwith type 2 diabetes (UKPDS 34). Lancet 1998;352: 854-65.

7. UK Prospective Diabetes Study (UKPDS) Group. Intensive blood glucose control with sulphonylureas or insulin compared with conventional treatment and risk of complications in patients with type 2 diabetes (UKPDS 33). Lancet 1998; 352: 837-53.

8. Patel B, Oza B, Patel KP, Malhotra SD, Patel VJ. Pattern of antidiabetic drugs use in type-2 diabetic patients in a medicine outpatient clinic of a tertiary care teaching hospital. Int J Basic ClinPharmacol2013; 2(4): 485-91.

9. Jimoh AO, Sabir AA, Chika A, Sani Z. Pattern of Antidiabetic Drugs Use in a Diabetic Outpatient Clinic of a Tertiary Health Institution in Sokoto, North-western Nigeria. Journal of Medical Sciences 2011; 11: 241-45.

10. Vengurlekar S, Shukla P, Patidar P, Bafna R, Jain S. Prescribing Pattern of Antidiabetic Drugs in Indore City Hospital. Indian J Pharm Sci 2008; 70(5): 637-40.

11. Abdi SAH, Churi S, Ravi Kumar YS. Study of drug utilization pattern of antihyperglycemic agents in a South Indian tertiary care teaching hospital. Indian J Pharmacol 2012; 44(2): 210-14.

12. Desai NR, Shrank WH, Fisher MA, Avorn J, Libeman JN, Schneeweiss S, et al. Pattern of medication initiation in newly diagnosed diabetes mellitus: quality and cost implications. Am J Med 2012 Mar;124(3):302.

13. Bennett WL, Maruthur NM, Singh S. Comparative effectiveness and safety of medications for type 2 diabetes: an update including new drugs and 2 drug combination. Ann Intern Med 2011; 154:602-13. 